\title{
Effects of Facial Isometric Exercise on Antioxidant Capacity
}

\author{
Ikuyo Orita1,2, Ikuhiro Morikita², Mayumi Watanabe1,3*, Zaigen ${ }^{1}{ }^{1}{ }^{1}$, Shigeyuki Kanai1 \\ ${ }^{1}$ Kansai University of Health Sciences, Osaka, Japan \\ ${ }^{2}$ Osaka University of Health and Sport Sciences, Osaka, Japan \\ ${ }^{3}$ Faculty of Science and Engineering, Chuo University, Tokyo, Japan \\ Email: ^watanabem62@gmail.com
}

How to cite this paper: Orita, I., Morikita, I., Watanabe, M., Oh, Z. and Kanai, S. (2021) Effects of Facial Isometric Exercise on Antioxidant Capacity. Health, 13, 11711180 .

https://doi.org/10.4236/health.2021.1311086

Received: December 29, 2020

Accepted: January 6, 2021

Published: November 8, 2021

Copyright (c) 2021 by author(s) and Scientific Research Publishing Inc. This work is licensed under the Creative Commons Attribution International License (CC BY 4.0).

http://creativecommons.org/licenses/by/4.0/

\begin{abstract}
Background: Facial isometric exercise is a static contraction of facial muscles without any visible movement in the angle of the joints. To examine the effects of facial isometric exercise on subjective stress and oxidative stress/antioxidant capacity. Methods: In this study, we included 13 participants (6 males, 7 females; average age, $44.8 \pm 19.6$ years; age range: 20 - 74 years) who were exposed to constant temperature and humidity in a room. Fifteen minutes after entering the room, the force was measured before and after facial isometric exercise of the target muscles: upper lip levator, small zygomatic, large zygomatic, levator animus, laughing, buccal, muzzle, mental, temporal, masseter, and cervical muscles), and further evaluated by comparing the facial isometric exercise group and control (non-facial isometric exercise) group (crossover test). Results: Subjective stress significantly improved by $8.7 \pm$ 16.3 in the facial isometric exercise group, and no significant difference in oxidative stress level was observed in both the groups. However, the antioxidant capacity significantly increased by $126.8 \pm 168.1 \mu \mathrm{mol} / \mathrm{l}$ in the facial isometric exercise group. Conclusion: The results of this study suggest that facial isometric exercise is an exercise therapy that can provide mental stability and antiaging effects due to improvement in subjective stress and biological antioxidant potential.
\end{abstract}

\section{Keywords}

Facial Isometric Exercise, Subjective Stress, Oxidative Stress Levels, Antioxidant Capacity

\section{Introduction}

Facial isometric exercise (FIE) is a static contraction of facial muscles without 
any visible movement in the angle of the joints. Thus, the advantage of FIE is that it can be performed wrinkle free by aerobic exercises, slowly contracting the muscles while fixing the facial muscle stop with the hand. In previous studies, FIE (9 types) was continuously performed 3 times on healthy participants whose facial skin temperatures were $\leq 34.0^{\circ} \mathrm{C}$, which resulted in increased blood flow and skin temperature at the corners of the mouth [1]. In a study conducted by Murad Alam et al., participants performed facial exercises (32 types; isotonic/isometric, unknown) for 20 weeks ( 8 weeks, 30 minutes/day; after 9 weeks, 30 minutes/day), and reported a significant improvement in the lower cheek fullness "bulge" [2].

In recent years, it has been observed that oxidative stress and antioxidation are associated with exercise. In recent years, it has been noted that oxidative stress (an imbalance between free radicals and antioxidants in the body) and antioxidation (the ability to remove active oxygen) are closely associated with exercise. In addition, it has been reported that the degree of oxidative stress (d-ROMs) and antioxidant capacity (BAP) differ according to the exercise load. Horse (Thoroughbred, 4 - 7 years old) treadmill (multistage exercise test, every 2 minutes [1.6, 3.6, $7,10,12,13$, and $14 \mathrm{~m} / \mathrm{sec}$; slope fat $6 \%$ speed). As a result, d-ROMs and BAP significantly increased immediately after the exercise [3]. However, no significant difference was observed in d-ROMs and BAP immediately after the treadmill exercise (ICR mice, male, 5 weeks old; $20 \mathrm{~m} / \mathrm{min}, 10^{\circ}$ tilt, 30 minutes). As reported, a significant increase in BAP as a result of 6 months of continuous exercise (twice a week) was observed [4].

Furthermore, cyclists (19 - 22 years, male) used bicycle ergometers to perform a multistage exercise test (every 3 minutes, $0.5 \mathrm{kp}$ load; $4 \mathrm{kp}$ or later, $0.3 \mathrm{kp}$ ) with a heart rate reserve strength of $70 \%$. As a result of aerobic exercise, d-ROMs showed no changes, while the BAP significantly increased from 1 hour after the stress test, and the effect continued for 1 hour after completion [5]. The d-ROMs and BAP may be closely associated with exercise load. FIE promotes the increase in blood flow and skin temperature at the corners of the mouth; therefore, it is expected that exercise performed by a specific body part or area and not the whole body may independently affect the BAP. In this study, we investigated the effects of our FIE program on subjective stress, oxidative stress (d-ROMs), and antioxidant potential (BAP).

\section{Methods}

\subsection{Participants}

We posted recruiting posters at the Kansai Medical University facility as well as clinics attached to the University from September 2018 to November 2018. And then we randomly recruited volunteers who interested in the FIE.

The participants were those who felt stress and those who felt weakened facial muscles and were in good physical condition. The participants were explained the purpose and methods of the study and the information of muscle fatigue that 
could be occurred as a result of the exercise. Afterwards, consent form was provided to participants. Excluded participants were those who had communication difficulties and were judged inappropriate by the doctor, and those who did not meet the schedule.

Conclusively 13 healthy participants participated in this study (Table 1). (6 males, 7 females; average age, $44.8 \pm 19.6$ years; age range: 20 - 74 years).

At the beginning, 15 participants volunteered, however, two of them discontinued due to poor physical condition and being unfit for schedule, respectively (Figure 1(a)).

\subsection{Crossover Study}

This study was designed using a crossover test. The participants were divided

Table 1. Characteristics of the participants.

\begin{tabular}{|c|c|c|}
\hline Characteristics & $\mathrm{n}$ & $\%$ \\
\hline Total & 13 & 100.00 \\
\hline \multicolumn{3}{|l|}{ Gender } \\
\hline Males & 6 & 46.20 \\
\hline Females & 7 & 53.80 \\
\hline \multicolumn{3}{|l|}{ Age group (years) } \\
\hline $20-29$ & 4 & 30.77 \\
\hline $30-39$ & 1 & 7.96 \\
\hline $40-49$ & 3 & 23.08 \\
\hline $50-59$ & 1 & 7.69 \\
\hline $60-69$ & 3 & 23.08 \\
\hline $70-79$ & 1 & 7.69 \\
\hline \multicolumn{3}{|l|}{ Occupationalstatus } \\
\hline Unemployed & 4 & 30.77 \\
\hline Worker & 4 & 30.77 \\
\hline Student & 5 & 38.46 \\
\hline \multicolumn{3}{|l|}{ Marital } \\
\hline Single & 5 & 38.50 \\
\hline Status married & 8 & 61.50 \\
\hline \multicolumn{3}{|l|}{ Physical condition } \\
\hline Good & 13 & 100.00 \\
\hline Bad & 0 & 0.00 \\
\hline
\end{tabular}

Participants sociodemographic and clinical characteristics were shown by gender, age, occupation, marital status, and physical condition. 


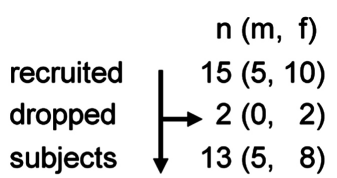

(a)

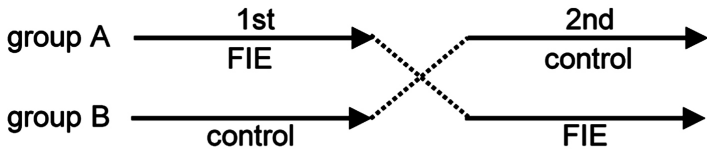

(b)

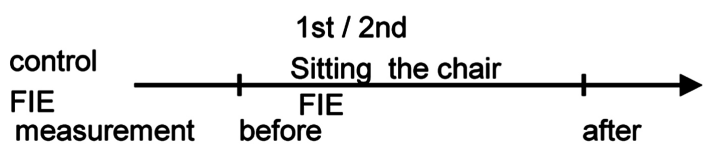

(c)

Figure 1. (a) Participants in this study, over view of subjects. Although 15 participants volunteered for the study, 2 discontinued due to poor physical condition and being unfit for schedule, respectively; (b) Image of the cross over study. We took more than one week between the first experiment and the second experiment; (c) The protocol of this study.

into the FIE group and control (non-FIE) group. We prepared more than one week between the first experiment and the second experiment as illustrated (Figure 1(b)).

Both the groups were at rest for the same period of time. After entering the room, the volunteers were seated in a chair for 15 minutes to adapt to the environment. And then we collected blood (Figure 1(c)).

The study was conducted in a constant temperature and humidity chamber $\left(25.0^{\circ} \mathrm{C} \pm 0.1^{\circ} \mathrm{C}, 55.0 \% \pm 0.1 \%\right.$, no wind $)$.

\subsection{Facial Isometric Exercise (FIE)}

The FIE program targeted muscles as illustrated (Figure 2) (3 sets; isometric contraction for 10 seconds, followed by a 10 second muscle relaxation).

The program was performed by aerobic exercise while grasping the muscle starting part or fixed part with the left and right fingers (thumb, index finger, middle finger, and palm) of the volunteer and conscious of the contracting muscle, under the supervision of the researcher.

\subsection{Subjective Stress-Visual Analog Scale (VAS)}

The subjective stress was determined by volunteers from 0 to 100 using the visual analog scale (VAS).

\subsection{Oxidative Stress-d-ROMs (U.CARR)}

The degree of oxidative stress was determined by conducting a reactive oxygen metabolite test and hydroperoxide concentration in blood (unit: U.CARR [1U.CARR = equivalent to $0.08 \mathrm{mg}$ hydrogen peroxide]) was measured following the previous study [6]. 


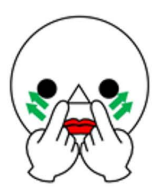

(a)

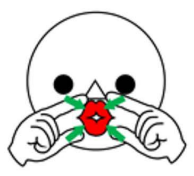

(e)

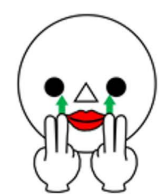

(b)

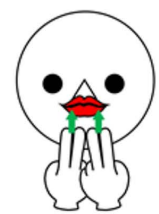

(f)

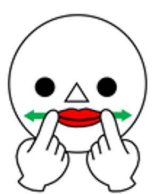

(c)

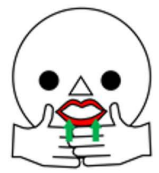

(g)

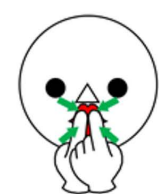

(d)

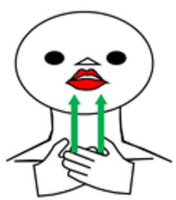

(h)

Figure 2. These figures show each exercise method. (a) Raise the cheek with index fingers. Fixed part: Nasolabial fold. Consciousness to muscles: Upper lip levator muscle, small and large zygomatic muscle. (b) Raise the corners of the mouth with index and middle fingers. Fixed part: Both corners of the mouthconscious muscles. Consciousness to muscles: Levatoranguli. (c) Spread the lip to both sides with index fingers. Fixed part: Both corners of the mouth. Consciousness to muscles: Risorius and buccinator muscle. (d) Draw the lips to the middle with index fingers. Fixed part: Upper and lower center of the lipsconscious muscle. Consciousness to muscles: buccinator muscle and orbicularis oris. (e) Close the slightly open lips with thumbs and index fingers. Fixed part: Upper and lower lip area. Consciousness to muscle: Orbicularis oris. (f) Raise the lower lip with index and middle fingers. Fixed part: Chin part. Consciousness to muscle: Mentalis. (g) Close the slightly open lips with palms. Fixed part: Lower jaw. Consciousness to muscles: Temporal and masseter muscle. (h) Raise the lower jaw (slight head extension) with palms. Fixed part: Both clavicles. Consciousness to muscles: Platysma muscle.

Blood $(100 \mu \mathrm{L})$ was collected from the fingertips of the participants under the supervision of a doctor and placed in a heparin blood collection tube and a free radical analyzer (Wismerll Co. Ltd., Japan, FREE carpe diem) Then, heparin plasma $(20 \mu \mathrm{L})$ was obtained by centrifugation ( $6000 \mathrm{rpm}, 2$ minutes).

In this procedure, heparin plasma $(20 \mu \mathrm{L})$ was mixed with acidic buffer $(\mathrm{pH}$ $4.8)$ and d-ROMs color solution $(20 \mu \mathrm{L})$, and the absorbance was then measured. The measurement was performed before and after the FIE.

\subsection{Antioxidant Capacity-BAP ( $\mu \mathrm{mol} / \mathrm{l})$}

Antioxidant capacity was measured by conducting a BAP test and measuring the reducing power according to the iron oxide ion concentration in the blood (unit: $\mu \mathrm{mol} / \mathrm{l})$. Here, heparin plasma $(10 \mu \mathrm{L})$ was mixed with the BAP color solution $(50 \mu \mathrm{L})$ and the absorbance was measured. The measurement was performed before and after the FIE.

\subsection{Statistical Analysis}

Statistical analysis was performed using statistical software (Stat View ver.4.5 HULINKS Inc.). Significance test was performed using Wilcoxon rank-sum test, with data expressed as mean \pm standard deviation (Mean \pm SD). Statistical signi- 
ficance is defined, ${ }^{\star} \mathrm{p}<0.05$.

\section{Results}

Table 2 shows the results, changes of FIE subjective stress (VAS), oxidative stress, and antioxidant capacity.

\subsection{Subjective Stress-Visual Analog Scale (VAS)}

The FIE group showed a significant improvement of $8.7 \pm 16.3(\mathrm{p}<0.05)$ while the control group showed an improvement trend of $3.5 \pm 7.7(\mathrm{p}=0.0995)$. There was no significant difference between the two groups (Figure 3 ).

\subsection{Oxidative Stress-d-ROMs (U.CARR)}

There was no significant change in d-ROMs in both the groups (Figure 4).

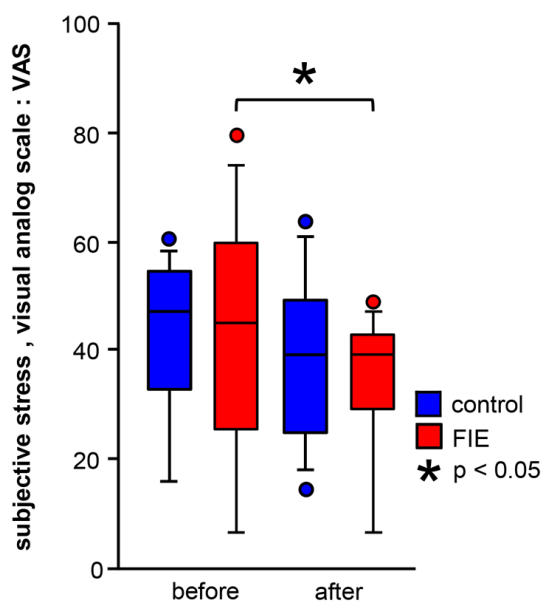

Figure 3. Box plot with scatter diagram of subjective stress (VAS) before and after FIE of the control group and FIE group: Subjective stress was significantly lower after FIE than in the control group $(\mathrm{p}<0.05)$.

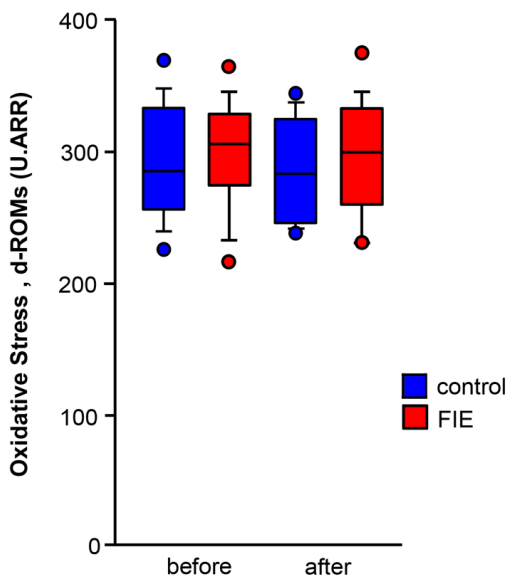

Figure 4. Box plot with scatter diagram of oxidative stress (d-ROMs) before and after FIE of the control group and FIE group: Oxidative stress was not significantly different before and after FIE in both groups. 
Table 2. Changes of FIE subjective stress, oxidative stress, and antioxidant capacity.

\begin{tabular}{ccccccc}
\hline \multirow{2}{*}{ Group } & \multicolumn{2}{c}{ subjective stress VAS } & \multicolumn{2}{c}{ oxidative stress d-ROMs (U.CARR) } & \multicolumn{2}{c}{ antioxidant capacity BAP ( $\mu$ mol/1) } \\
\cline { 2 - 7 } & before & after & before & after & before & after \\
\hline Control & $42.1 \pm 17.4$ & $38.6 \pm 15.9$ & $287.9 \pm 44.5$ & $286.5 \pm 40.0$ & $1.943 .7 \pm 239.7$ & $1.897 .5 \pm 319.6$ \\
FIE & $42.2 \pm 23.7$ & $33.4 \pm 14.7^{*}$ & $296.9 \pm 41.6$ & $296.4 \pm 45.2$ & $1.942 .3 \pm 284.1$ & $2.069 .2 \pm 211.2^{\star}$ \\
\hline
\end{tabular}

In the FIE (facial isometric exercise) group, subjective stress improved significantly, and no significant difference was observed in the d-ROMs (the degree of oxidative stress). However, a significant increase in the BAP (antioxidant capacity) was noted. $\mathrm{n}=13$. Mean \pm SD Wilcoxon signed-rank test, ${ }^{*} \mathrm{p}<0.05$.

\subsection{Antioxidant Capacity-BAP ( $\mu \mathrm{mol} / \mathrm{l})$}

The FIE group showed a significant increase of $126.8 \pm 168.1 \mu \mathrm{mol} / \mathrm{l}(\mathrm{p}<0.05)$ while the control group did not $(\mathrm{p}=0.2787)$. There was a tendency of separation between the two groups after the FIE (before, $p=0.9721$; after, $p=0.0640$ ) (Figure 5).

\section{Discussion}

Based on the results of our study, we recommend the FIE program as an exercise therapy because it can increase subjective resistance without changing the oxidative stress and improving the subjective stress by slowly performing three sets at a time. Anaerobic exercise is a method of enhancing physical ability by simultaneously increasing both the d-ROMs and BAP [7], but FIE trains facial muscles to suppress the increase in $\mathrm{d}-\mathrm{ROMs}$ and BAP.

An antiaging effect can be expected. Besides exercise, "laughter" also affects stress [8], which includes "spontaneous laughter," "intentional smile," and "mechanical smile." During "spontaneous laughter," there is an increase in electrodermal activity and the sympathetic nervous system reacts. It can be expected to increase and antioxidant by controlling the autonomic nervous system because it increases and declines rapidly in the recovery period [9], but in "laughter," passive items [human, talking partner; means, comics, rakugo (a kind of traditional Japanese comedy), movies, plays, etc.] are required to actively promote antioxidants. In contrast, FIE does not need passive items to actively promote antioxidants.

In the maintenance of a human body, signal transmission and physiological functions of reactive oxygen species (ROS) are important. When ROS reacts with biological macromolecules without excessively producing ROS and decomposing/removing active oxygen by antioxidant enzymes, cell dysfunction (lipid peroxidation, DNA mutation, protein denaturation, enzyme inactivation) causes oxidative stress (the balance between active oxygen generation and elimination collapses and leans toward oxidation) [10]. d-ROMs and BAP are used as indicators of lifestyle-related disease prevention and conditioning prior to sports competition. In lifestyle-related diseases, visceral fat area and BAP are positively correlated and creatinine is negative correlated with d-ROMs as the axis [11]. FIE is better suited for pre-sport conditioning than lifestyle-related illnesses 


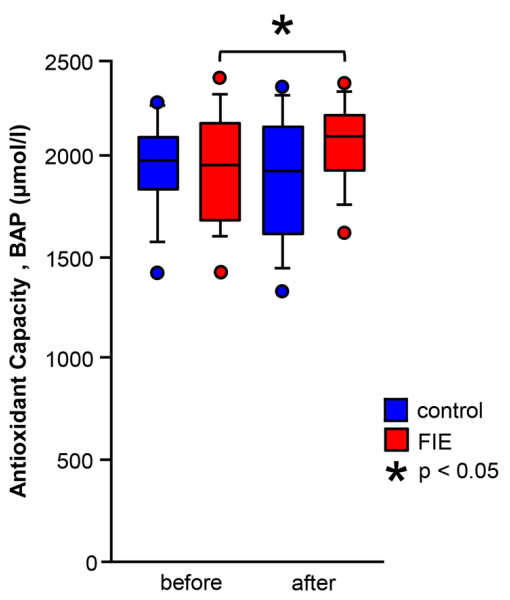

Figure 5. Box plot with scatter diagram of antioxidant capacity (BAP) before and after FIE of the control group and FIE group: Antioxidant increased significantly after FIE in the FIE group $(\mathrm{p}<0.05)$.

because it has been reported to be a desirable pre-game condition with low oxidative stress and high antioxidant capacity [12]. Many athletes adopt stretch [13], mindfulness [14], music appreciation [15], and so on as methods to increase concentration just before the competition, and FIE is considered to be ineffective here.

\section{Conclusion}

It was suggested that the FIE program in this study has mental stability and antiaging effects, and can be applied to conditioning before sports competition. We understand this study warrants further research on the type of sports the program is most suitable for.

\section{Acknowledgements}

The authors thank all of the subjects and staff who participated in this study.

\section{Ethical Approval}

This study was approved by the Ethics Review Board of Kansai University of Health Sciences (Osaka, Japan: process number 18-05).

\section{Conflicts of Interest}

The authors declare no conflicts of interest regarding the publication of this paper.

\section{References}

[1] Orita, I. and Kanai, S. (2015) Effect of Effective Facial Exercise on Skin Surface Temperature. Biomedical Thermology, 34, 44-48.

[2] Alam, M., Walter, A.J., Geisler, A., Roongpisuthipong, W., Sikorski, G., Tung, R., et al. (2018) Association of Facial Exercise with the Appearance of Aging. JAMA Der- 
matology, 154, 365-367. https://doi.org/10.1001/jamadermatol.2017.5142

[3] Tsubone, H., Hanafusa, M., Endo, M., Manabe, N., Higasa, A.,Ohmura, H., et al. (2013) Effect of Treadmill Exercise and Hydrogen-Rich Water Intake on Serum Oxidative and Anti-Oxidative Metabolites in Serum of Thoroughbred Horses. Journal of Equine Science, 24, 1-8. https://doi.org/10.1294/jes.24.1

[4] Maruoka, H. and Fujii, K. (2011) Effect of the Reduced Coenzyme Q10 and Exercise Training on the Oxidative Stress Regulation System and Exercise Capacity in Mice. Japanese Journal of Complementary and Alternative Medicine, 8, 85-97. https://doi.org/10.1625/jcam.8.85 https://www.jstage.jst.go.jp/article/jcam/8/2/8 $2285 / \mathrm{pdf} /-$ char/ja

[5] Nagashima, M. (2011) Effects of Endurance Exercise on Oxidative Stress and Antioxidant Vitamin Level in Trained Cyclists. The Japanese Journal of Physical Fitness and Sports Medicine, 60, 279-286. https://doi.org/10.7600/jspfsm.60.279

[6] Fryer, S., Stoner, L., Stone, K., Gile, D., Sveen, J., Garrido, I., et al. (2016) Forearm Muscle Oxidative Capacity Index Predicts Sport Rock-Climbing Performance. European Journal of Applied Physiology, 116, 1479-1484.

https://doi.org/10.1007/s00421-016-3403-1

[7] Wiecek, M., Szymura, J., Maciejczyk, M., Kantorowicz, M. and Szygula, Z. (2018) Anaerobic Exercise-Induced Activation of Antioxidant Enzymes in the Blood of Women and Men. Frontiers in Physiology, 9, Article No. 1006. https://doi.org/10.3389/fphys.2018.01006

[8] JongEun, Y. (2016) Therapeutic Benefits of Laughter in Mental Health: A Theoretical Review. Potential Therapeutic Benefits of Laughter in Mental Health, 239, 243 249. https://doi.org/10.1620/tjem.239.243

[9] Ishihara, S. (2007) Experimental Study of Spontaneous Laughter and Its Effect on the Autonomic Nervous System. Bunkyou University Faculty of Human Sciences, 29, 51-59.

https://warp.da.ndl.go.jp/info:ndljp/pid/284033/www.bunkyo.ac.jp/faculty/lib/klib/ kiyo/hum/h29/h2904.pdf

[10] Burtenshaw, D., Kitching, M., Redmond, E.M., Megson, I.L. and Cahill, P.A. (2019) Reactive Oxygen Species (ROS), Intimal Thickening, and Subclinical Atherosclerotic Disease. Frontiers in Cardiovascular Medicine, 6, Article No. 89. https://doi.org/10.3389/fcvm.2019.00089

[11] Fukui, T., Yamauchi, K., Maruyama, M., Yasuda, T., Kohno, M. and Abe, Y. (2011) Significance of Measuring Oxidative Stress in Lifestyle-Related Diseases from the Viewpoint of Correlation between d-ROMs and BAP in Japanese Subjects. Hypertension Research, 34, 1041-1045. https://doi.org/10.1038/hr.2011.76

[12] Pingitore, A., Lima, G., Mastorci, F., Quinones, A., Iervasi, G. and Vassalle, C. (2015) Exercise and Oxidative Stress: Potential Effects of Antioxidant Dietary Strategies in Sports. Nutrition, 31, 916-922.

https://www.sciencedirect.com/science/article/abs/pii/S0899900715000738?via\%3Di $\underline{\text { hub }}$

[13] Heisey, C.F. and Kingsley, J.D. (2016) Effects of Static Stretching on Squat Performance in Division I Female Athletes. International Journal of Exercise Science, 9, 359-367.

[14] Amemiya, R., Kim, E., Inagaki, K. and Sakairi, Y. (2019) Mindfulness and Psychological Competitive Abilities Promotes the Mental Health of Athletes. Japanese Journal of Sport Psychology, 46, 67-80. https://doi.org/10.4146/ijspopsy.2019-1802

[15] Arazi, H., Asadi, A. and Purabed, M. (2015) Physiological and Psychophysical Res- 
ponses to Listening to Music during Warm-Up and Circuit-Type Resistance Exercise in Strength Trained Men. Journal of Sports Medicine, 2015, Article ID: 389831. https://doi.org/10.1155/2015/389831 